\title{
MENSURAÇÃO DA CONDUTIVIDADE ELÉTRICA DO SOLO POR INDUÇÃO E SUA CORRELAÇÃO COM FATORES DE PRODUÇÃO
}

\author{
JOSÉ P. MOLIN ${ }^{1}$, LEANDRO M. GIMENEZ ${ }^{2}$, VOLNEI PAULETTI ${ }^{2}$, \\ URS SCHMIDHALTER ${ }^{3}$, JENS HAMMER ${ }^{4}$
}

\begin{abstract}
RESUMO: A condutividade elétrica (CE) do solo, obtida por contato ou por indução eletromagnética, tem sido utilizada como uma variável que se correlaciona com características do solo. Investigaram-se as relações existentes entre a CE medida com um sensor de indução eletromagnética, a granulometria do solo, umidade e fatores da fertilidade, a topografia do terreno e a produtividade de milho e soja, em uma lavoura de 19 ha, conduzida sob semeadura direta, entre 2000 e 2002. A produtividade das culturas foi obtida com monitor comercial, e a $\mathrm{CE}$ e os demais parâmetros foram obtidos por amostragem em grade regular. Os dados foram espacializados para a produção dos mapas que serviram para a análise de correlações entre os fatores. O sensor de condutividade elétrica mostrou-se limitado para a leitura na ausência de um coletor de dados, dificultando a coleta de dados com maior frequiência e densidade, além de exigir freqüentes calibrações. A CE apresentou forte dependência espacial, porém com correlação inversa entre as duas profundidades monitoradas. Os teores de argila e umidade do solo tiveram correlações positivas, porém abaixo do esperado, somente para as leituras superficiais de CE.
\end{abstract}

PALAVRAS-CHAVE: agricultura de precisão, variabilidade espacial, fatores de produção.

\section{ELECTRICAL CONDUCTIVITY BY INDUCTION AND ITS CORRELATION WITH YIELD CROP FACTORS}

\begin{abstract}
Soil electrical conductivity obtained by contact or induction sensors has been used as a variable that correlates with soil characteristics of interest on spatial variability analysis. This work reports the experience done in a 19 ha no-till field aiming to correlate soil electrical conductivity (EC) measured by an induction sensor and soil chemical fertility properties, soil texture, altitude, humidity, soil fertility and corn and soybean yield between 2000 and 2002. Yield data was obtained using a yield monitor; EC and the other parameters were sampled based on a regular grid. Data were submitted to a spatial analysis generating maps for correlation analysis among the factors. EC sensor was limited on its operation, especially for not having a data logger, and requiring frequent calibrations. EC data were strongly spatially dependent but with inverse correlation between the two reading depths. Clay and water content resulted in positive correlations with EC in the shallow reading but at levels lower than expected.
\end{abstract}

KEYWORDS: precision agriculture, spatial variability, yield factors.

\footnotetext{
${ }^{1}$ Eng ${ }^{\mathbf{o}}$ Agrícola, Prof. Doutor, Departamento de Engenharia Rural, ESALQ/USP, Piracicaba - SP, jpmolin@ esalq.usp.br

${ }^{2}$ Eng $^{-}$Agrônomo, Pesquisador, Fundação ABC, Castro - PR.

${ }^{3}$ Prof., Instituto de Nutrição de Plantas, Technische Universitaet Muenchen, Freising, Alemanha.

${ }^{4}$ Estudante de Agronomia, Instituto de Nutrição de Plantas, Technische Universitaet Muenchen, Freising, Alemanha.

Recebido pelo Conselho Editorial em: 20-11-2003

Aprovado pelo Conselho Editorial em: 7-7-2005
} 


\section{INTRODUÇÃO}

A agricultura de precisão preconiza que o manejo das lavouras pode ser melhor conduzido se a variabilidade espacial da produtividade e dos fatores a ela relacionados forem conhecidos. Esses fatores podem ser tratados localizadamente ou as lavouras podem ser divididas em unidades de gerenciamento diferenciado.

Recursos para gerar mapas de produtividade de grãos ou várias outras culturas já são disponíveis para o usuário (MOLIN, 2000). No entanto, o correto entendimento das variáveis, associadas à variabilidade espacial da produtividade dentro de um talhão, ainda é deficiente. As correlações existentes entre a variável dependente (produtividade) e os fatores de produção, muitas vezes relacionados aos componentes da fertilidade do solo, normalmente são bastante baixos (MOLIN et al., 2001), e as tentativas de explicar os fenômenos locais com alguns poucos fatores são frustradas. ACOCK \& PACHEPSKY (1997) consideram que as relações entre solo, planta e ambiente são melhor entendidas utilizando-se de ferramentas de modelagem. Porém, como o conhecimento do comportamento das plantas não está suficientemente dominado, esses modelos ainda não respondem a contento.

Além dos mapas de produtividade, outras investigações podem auxiliar na definição de unidades de gerenciamento diferenciado. Estudos com o uso da condutividade elétrica do solo têm apontado seu potencial para a mensuração de conteúdo de argila (WILLIAMS \& HOEY, 1987), conteúdo de água (KACHANOSKI et al., 1988), capacidade de troca catiônica e teores de cálcio e magnésio trocáveis (McBRIDE et al., 1990), profundidade de camada de impedimento (DOOLITTLE et al., 1994 e CLARK et al., 2000), teor de matéria orgânica (JAYNES, 1996), teor de sais da solução do solo (CAMINHA JUNIOR et al., 1998), dentre outros.

A condutividade elétrica do solo pode ser medida por contato, fazendo passar uma corrente elétrica em eletrodos isolados, ou indiretamente, com o uso de corrente induzida por um campo magnético, sem contato com o solo. Para ambos os casos, existem equipamentos comerciais que foram testados e mostraram resultados semelhantes (FRITZ et al., 1998; SUDDUTH et al., 1998; BUCHLEITER \& FARAHANI, 2002). HARTSOCK et al. (2000) trabalharam com um sensor de condutividade elétrica por contato, disponível no mercado, e observaram variabilidade temporal nos níveis de condutividade elétrica. No entanto, as tendências se mantiveram, indicando seu uso potencial para a detecção de regiões ou unidades que podem ser tratadas diferentemente.

Este trabalho relata o monitoramento de uma lavoura ao longo de dois ciclos, um de milho e um de soja, durante as safras de 2000-2001 e 2001-2002, onde foram coletados dados de produtividade e de altimetria, amostras de solo em diferentes grades regulares para análise de características físicas e químicas do solo, bem como a condutividade elétrica medida com um sensor de condutividade elétrica por indução, paralelamente ao teor de água do solo medido por secagem das amostras.

\section{MATERIAL E MÉTODOS}

Foi selecionada uma lavoura de 19 ha, no município de Carambei - PR, com latitude 2453'S e longitude $50^{\circ} 16^{\prime} \mathrm{W}$, conduzida em sistema de semeadura direta, há 11 anos, e sobre um solo com transições entre Latossolo Vermelho, Cambissolo Háplico e Neossolo Litólico (BOGNOLA \& FASOLO, 2003). Os dados para a obtenção dos mapas de produtividade da cultura de milho da safra 2000-2001 e da cultura da soja na safra 2001-2002 foram obtidos com um monitor New Holland ${ }^{\circledR}$ PLMS associado a um receptor de GPS Trimble ${ }^{\circledR}$ Ag 132 com sinal diferencial Omnistar ${ }^{\circledR}$, em tempo real, via satélite. Todos os equipamentos estavam instalados em uma colhedora New Holland modelo TC 57.

Juntamente com a coleta dos dados de produtividade, o monitor também registrou os dados de altitude de cada ponto. Embora seja uma informação de acurácia limitada, foi utilizada apenas para 
caracterizar o acentuado desnível topográfico existente no talhão, e os pontos foram interpolados para a obtenção de mapas topográficos de altimetria.

Com o auxílio do sistema de informação geográfica dedicado à Agricultura de Precisão SSToolbox (SST Development Group ${ }^{\circledR}$ ), foram definidas as malhas amostrais. Inicialmente, foi definida uma malha regular de $35 \mathrm{~m}$ de lado para as leituras de condutividade elétrica do solo, resultando em aproximadamente 8,1 leituras por hectare. Essa mesma malha foi utilizada para a coleta de amostras de solo para análise de textura e de teor de água no solo, porém intercalando pontos em malha de $70 \mathrm{~m}$ de lado, resultando em aproximadamente 2,0 amostras por hectare. A coleta das amostras e a leitura dos valores da condutividade elétrica do solo foram realizadas em abril de 2001, imediatamente após a colheita da cultura do milho. Nova amostragem em grade regular com $60 \mathrm{~m}$ de lado, resultando em aproximadamente 2,8 amostras por hectare, foi elaborada para a coleta de amostras para a análise química de rotina em laboratório. Essa coleta foi realizada em setembro de 2001, antes da semeadura da cultura da soja.

Para a navegação aos pontos nas diferentes amostragens e leituras, foi utilizado um receptor de GPS Trimble Ag 132 e sinal diferencial Racal ${ }^{\circledR}$, em tempo real, via satélite, conectado a um computador de mão $\mathrm{HP}^{\circledR}$ Jornada 548 , equipado com o programa de navegação Farm Site Mate (FarmWorks Software ${ }^{\circledR}$ ).

A condutividade elétrica do solo foi determinada utilizando-se de sensor por indução magnética Geonics EM-38 (Geonics Limited ${ }^{\circledR}$ ). O equipamento permite a leitura da condutividade elétrica da superfície do solo até $0,30 \mathrm{~m}$ quando na posição vertical e da superfície do solo até $1,50 \mathrm{~m}$, quando na posição horizontal. No entorno de cada ponto, em um raio de 2,0 m, foram executadas cinco leituras em cada camada, compondo a média representativa de cada ponto para cada camada. Como o equipamento apresenta um visor digital, as leituras foram feitas individualmente e anotadas manualmente. $\mathrm{O}$ equipamento foi calibrado previamente à coleta dos dados, conforme recomendação do fabricante, afastado de qualquer material metálico, da mesma forma que durante a sua utilização em campo.

As amostras para a determinação do teor de água e da textura do solo foram coletadas no mesmo dia em que foram feitas as leituras de condutividade elétrica, sendo compostas por quatro subamostras obtidas com amostrador manual tipo calador, com amostragem de 0 a 0,20 m e de 0,20 a 0,40 m de profundidade. As análises de textura do solo foram obtidas em laboratório pelo método de dispersão total e a determinação do teor de água das amostras foi feita pelo método da estufa, com secagem a $104{ }^{\circ} \mathrm{C}$ durante 30 horas.

A amostragem para a análise química de rotina em laboratório foi obtida com amostrador mecânico-hidráulico de broca, transportado por um quadriciclo. No entorno de cada ponto, foram coletadas oito subamostras em um raio de aproximadamente $3,0 \mathrm{~m}$ e na profundidade de 0 a $0,10 \mathrm{~m}$. Foram utilizados os dados das análises de teores de matéria orgânica, $\mathrm{pH}$ em solução de $\mathrm{CaCl}_{2}$, soma de bases, capacidade de troca de cátions (CTC) e saturação por bases (V\%).

Os dados de condutividade elétrica e das características físico-químicas do solo foram submetidos à análise estatística descritiva e geoestatística com a utilização do programa GS+ (Gamma Design Software ${ }^{\circledR}$ ). Na seqüência, foram espacializados utilizando o método de krigagem com o programa SSToolbox para a produção das superfícies matriciais (mapas "raster") com células de $10 \mathrm{~m}$ de lado. Da mesma forma, os dados de produtividade também foram espacializados com células do mesmo tamanho, porém utilizando o método de interpolação do inverso da distância, em função do elevado número de dados, de aproximadamente 830 pontos por hectare, conforme sugerido por MOORE (1998), após o processo de filtragem para eliminação de pontos com valores improváveis, segundo GIMENEZ \& MOLIN (2000). 
Os valores obtidos foram utilizados para a análise de correlações entre os fatores, realizada no próprio sistema de informação geográfica. Gerou-se matriz de correlação envolvendo todos os fatores, a qual permitiu a análise das tendências da relação entre cada par de fatores.

\section{RESULTADOS E DISCUSSÃO}

O sensor por indução magnética utilizado apresentou dificuldades operacionais com freqüente necessidade de recalibração, atribuída à variação da temperatura ambiente ao longo do período. Essa característica, associada ao fato de que o sensor não possui coletor de dados, o torna pouco prático para uso mais intensivo e visando a cobrir extensas áreas. Para implementar a coleta de dados de forma automática, contínua e em grande densidade de leituras, é necessária a adaptação de um coletor de dados e de um sistema de transporte sobre rodas ou por deslizamento e isento de materiais ferrosos. As leituras efetuadas resultaram em valores de escala negativos, especialmente para a CE de 0 a $0,30 \mathrm{~m}$. Apenas para a espacialização e conseqüente análise de correlação, optou-se por adicionar uma constante e trabalhar apenas com valores positivos.

Ao todo, foram incluídos 18 fatores na análise de correlação, incluindo a condutividade elétrica do solo nas duas profundidades de leitura, os fatores da análise química, os componentes da textura e o teor de água do solo nas duas profundidades amostradas e os resultados das duas colheitas. Na Tabela 1, são apresentados os resultados da análise estatística dos dados obtidos por amostragem em grade regular e, na Tabela 2, são apresentados os resultados da análise geoestatística dos mesmos dados.

TABELA 1. Estatística descritiva dos dados analisados.

\begin{tabular}{|c|c|c|c|c|c|c|c|}
\hline Fator & $\begin{array}{l}\text { Profundidade } \\
\text { (m) }\end{array}$ & $\mathrm{N}$ & Média & Mediana & Mínimo & Máximo & $\begin{array}{l}\text { Desvio- } \\
\text { Padrão }\end{array}$ \\
\hline Matéria orgânica $\left(\mathrm{g} \mathrm{dm}^{-3}\right)$ & 0 a 0,10 & 54 & 42,6 & 42,5 & 18,0 & 78,0 & 14,3 \\
\hline $\mathrm{pH}$ & 0 a 0,10 & 54 & 5,3 & 5,2 & 4,6 & 5,8 & 0,3 \\
\hline Soma de bases $\left(\mathrm{mmol}_{\mathrm{c}} \mathrm{dm}^{-3}\right)$ & 0 a 0,10 & 54 & 87,2 & 87,0 & 46,2 & 140,4 & 22,1 \\
\hline $\mathrm{CTC}\left(\mathrm{mmol}_{\mathrm{c}} \mathrm{dm}^{-3}\right)$ & 0 a 0,10 & 54 & 127,0 & 123,6 & 70,1 & 185,1 & 29,6 \\
\hline $\mathrm{V}(\%)$ & 0 a 0,10 & 54 & 68,9 & 69,0 & 46,0 & 86,0 & 8,1 \\
\hline Umidade (\%) & 0 a 0,20 & 34 & 20,9 & 20,0 & 13,5 & 29,7 & 4,9 \\
\hline Umidade (\%) & 0,20 a 0,40 & 34 & 22,6 & 22,2 & 13,0 & 34,2 & 5,8 \\
\hline Argila $(\%)$ & 0 a 0,20 & 34 & 31,6 & 28,0 & 12,6 & 55,8 & 12,7 \\
\hline Argila (\%) & 0,20 a 0,40 & 34 & 35,3 & 31,4 & 0,0 & 60,0 & 14,9 \\
\hline Silte $(\%)$ & 0 a 0,20 & 34 & 16,8 & 17,0 & 5,3 & 31,8 & 7,4 \\
\hline Silte (\%) & 0,20 a 0,40 & 34 & 15,8 & 16,2 & 0,0 & 36,3 & 7,8 \\
\hline Areia $(\%)$ & 0 a 0,20 & 34 & 51,6 & 53,3 & 18,4 & 82,1 & 19,4 \\
\hline Areia $(\%)$ & 0,20 a 0,40 & 34 & 46,0 & 49,1 & 0,0 & 79,8 & 20,9 \\
\hline 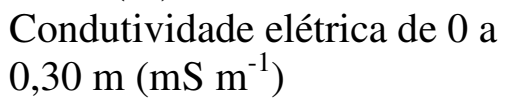 & 0 a 0,30 & 135 & $-3,0$ & $-6,1$ & 0,1 & 0,5 & $-29,9$ \\
\hline 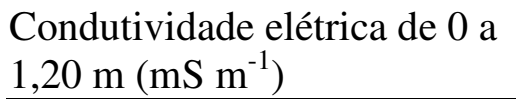 & 0 a 1,50 & 135 & 15,1 & 12,5 & 17,7 & 12,3 & 7,1 \\
\hline
\end{tabular}

Observa-se a tendência de gradiente textural com elevação dos teores de argila e equivalente redução dos teores de areia entre a amostragem superficial $(0-0,2 \mathrm{~m})$ e aquela profunda $(0,2-0,4 \mathrm{~m})$. A umidade do solo apresentou-se com valores levemente superiores na amostragem mais profunda.

Uma constatação indesejada foi o fato de o equipamento apresentar grande dificuldade de calibração e de manutenção dessa calibração, e os resultados apresentaram elevado número de leituras de condutividade elétrica do solo com valores negativos na profundidade de 0 a $0,3 \mathrm{~m}$. Isso pode 
caracterizar valores muito baixos para a variável, porém as leituras negativas não são reais e não foram utilizadas na análise de espacialização.

TABELA 2. Parâmetros geoestatísticos dos dados analisados.

\begin{tabular}{|c|c|c|c|c|c|c|}
\hline Fator & $\begin{array}{l}\text { Profundidade } \\
\text { (m) }\end{array}$ & Modelo & $\begin{array}{c}\text { Ef. pepita } \\
\text { C0 }\end{array}$ & $\begin{array}{l}\text { Patamar } \\
\mathrm{C} 0+\mathrm{Cl}^{*}\end{array}$ & $\begin{array}{l}\text { Alcance } \\
\text { (m) }\end{array}$ & $\frac{\mathrm{C} 1}{\mathrm{C} 0+\mathrm{C} 1}$ \\
\hline Matéria orgânica $\left(\mathrm{g} \mathrm{dm}^{-3}\right)$ & 0 a 0,10 & Esférico & 25,00 & 460,90 & 808,9 & 0,95 \\
\hline $\mathrm{pH}$ & 0 a 0,10 & Esférico & 0,04 & 0,13 & 717,8 & 0,69 \\
\hline Soma de bases $\left(\mathrm{mmol}_{\mathrm{c}} \mathrm{dm}^{-3}\right)$ & 0 a 0,10 & Esférico & 188,00 & 968,30 & 865,5 & 0,81 \\
\hline $\mathrm{CTC}\left(\mathrm{mmol}_{\mathrm{c}} \mathrm{dm}^{-3}\right)$ & 0 a 0,10 & Esférico & 52,00 & $1.983,00$ & 758,7 & 0,97 \\
\hline $\mathrm{V}(\%)$ & 0 a 0,10 & Exponencial & 12,70 & 56,12 & 35,6 & 0,77 \\
\hline \multirow{2}{*}{ Umidade $(\%)$} & 0 a 0,20 & Esférico & 2,90 & 31,28 & 327,5 & 0,91 \\
\hline & 0,20 a 0,40 & Esférico & 0,10 & 37,26 & 225,2 & 1,00 \\
\hline \multirow{2}{*}{ Argila (\%) } & 0 a 0,20 & Esférico & 42,60 & 304,40 & 647,7 & 0,86 \\
\hline & 0,20 a 0,40 & Exponencial & 124,80 & 339,40 & 257,2 & 0,63 \\
\hline \multirow{2}{*}{ Silte $(\%)$} & 0 a 0,20 & Exponencial & 0,10 & 76,99 & 149,8 & 1,00 \\
\hline & 0,20 a 0,40 & Esférico & 15,10 & 65,59 & 149,5 & 0,77 \\
\hline \multirow{2}{*}{ Areia $(\%)$} & 0 a 0,20 & Esférico & 85,00 & 585,70 & 487,6 & 0,85 \\
\hline & 0,20 a 0,40 & Esférico & 157,00 & 608,40 & 476,0 & 0,74 \\
\hline \multirow{2}{*}{ Condutividade elétrica $\left(\mathrm{mS} \mathrm{m}^{-1}\right)$} & 0 a 0,30 & Esférico & 8,30 & 51,87 & 281,5 & 0,84 \\
\hline & 0 a 1,20 & Esférico & 12,15 & 26,66 & 255,6 & 0,54 \\
\hline
\end{tabular}

C1 - componente estrutural do semivariograma

$\mathrm{Da}$ análise geoestatística dos dados, observa-se que o componente estrutural $[\mathrm{C} 1 /(\mathrm{C} 0+\mathrm{C} 1)]$, que indica a variação total dos dados explicada pela continuidade espacial, resultou em elevadas dependências espaciais (acima de 0,75), segundo CAMBARDELLA et al. (1994), para boa parte das variáveis e de média dependência espacial (entre 0,25 e 0,75) apenas para as variáveis pH, argila e areia de 0,2 a 0,4 m e CE de 0 a 1,2 m. Com exceção da saturação por bases (V\%), os alcances, que compreendem as distâncias dentro das quais há dependência espacial entre as amostras, foram superiores ao espaçamento entre essas amostras.

A matriz de correlação entre todos os dados envolvidos na análise é apresentada na Tabela 3. A CE do solo medida de 0 a 0,3 m teve correlação inversa $(-0,75)$ com aquela medida de 0 a $1,2 \mathrm{~m}$ de profundidade. Isso pode estar associado à elevada diferença na constituição do perfil do solo entre as duas camadas monitoradas. No entanto, como não foi monitorada a umidade abaixo de 0,40 m, essa também pode ter influenciado as diferenças de leituras na $\mathrm{CE}$. As correlações da umidade do solo de 0 a 0,20 e de 0,20 a 0,40 m foram positivas e semelhantes $(0,27$ e 0,26, respectivamente) com a CE lida de 0 a 0,3 $\mathrm{m}$ de profundidade. Como se pode observar na Tabela 1, os valores de umidade tiveram pouca alteração entre as duas camadas monitoradas. Como consequiência da correlação inversa entre as duas profundidades de leitura da $\mathrm{CE}$, a correlação entre essa variável e as demais seguiu a tendência de valores de correlação inversa.

Embora o fabricante do sensor estabeleça as duas profundidades como mencionado, sabe-se que não há limitantes determinados e sim regiões de maior resposta ao campo eletromagnético gerado. As espessuras dessas camadas são de transição tênue, e a leitura da camada mais espessa (0-1,2 m) é influenciada pelas características, também, da camada superficial (0-0,3 m).

A correlação entre a CE e o teor de argila na camada de 0 a $0,20 \mathrm{~m}$ foi de apenas 0,15 . Já na camada mais profunda, de 0,20 a 0,40 m, a correlação atingiu 0,33. Embora sejam significativos, esses valores não corresponderam ao observado por BANTON et al. (1997), que obtiveram correlações de 
0,64 e 0,53 entre a resistência elétrica, para teor de argila em solo seco e úmido, respectivamente, bem como DALGAARD et al. (2001), que obtiveram resultados em que a CE explicava $79 \%$ da variabilidade do teor de argila do solo.

Os dados de produtividade de milho e de soja demonstraram a grande variabilidade que tem sido observada em várias outras experiências do gênero e em condições semelhantes de solo e clima. Também apresentaram grandes diferenças entre as regiões e níveis de produtividade, representados pela correlação de 0,38 entre os dois mapas. Houve correlação significativa apenas entre a produtividade de milho e a $\mathrm{CE}$ de 0 a $0,30 \mathrm{~m}$, porém de apenas 0,16 .

Os dados de altimetria se repetiram entre os levantamentos obtidos nos dois anos, resultando em correlação de 0,99 e demonstram que o talhão apresenta declividades de até $15 \%$, representado no exemplo do limite superior de topografia acidentada em áreas mecanizadas da região. Os desníveis topográficos são acentuados e estão associados à formação dos solos da região, relacionando-se com a intensa variabilidade local, tanto das produtividades das lavouras, quanto dos fatores de solo das áreas.

\section{CONCLUSÕES}

A distribuição dos valores de condutividade elétrica lida de 0 a $0,30 \mathrm{~m}$ e de 0 a $1,20 \mathrm{~m}$ apresentou forte dependência espacial, porém os valores foram bastante discrepantes na lavoura, com correlação inversa, indicando a influência de algum fator não-monitorado.

Os teores de argila e umidade do solo, que são os fatores que mais se associam à condutividade elétrica, monitorados nas camadas de 0 a 0,20 e de 0,20 a $0,40 \mathrm{~m}$, tiveram correlação positiva, porém abaixo do esperado.

O sensor de condutividade elétrica por indução utilizado mostrou-se limitado para a leitura na ausência de um coletor de dados, dificultando a coleta de dados com maior frequiência e densidade, além de exigir freqüentes calibrações.

\section{REFERÊNCIAS}

ACOCK B.; PACHEPSKY, YA. Holes in precision farming: mechanistic crop models. In: EUROPEAN CONFERENCE ON PRECISION AGRICULTURE, 1., 1997, London. Proceedings.... London: SCI, 1997. p.397-404.

BANTON, O.; SEGUIN, M.K.; CIMON, M.A. Mapping field-scale physical properties of soil with electrical resistivity. Soil Science Society of American Journal, Madison, v.61, p.1010-17, 1997.

BOGNOLA, I.A.; FASOLO, P.J. Relatório de levantamento pedológico detalhado da "área-piloto de agricultura de precisão" de propriedade de J. Dijkstra, município de Carambei-PR. Curitiba: EMBRAPA, 2003. 43 p. (Relatório interno).

BUCHLEITER, G.W.; FARAHANI, H. Comparison of electrical conductivity measurements from two different sensing technologies. St. Joseph: ASAE, 2002. 9 p. (Paper 021056).

CAMBARDELLA, C.A.; MOORMAN, T.B.; NOVAK, J.M.; PARKIN, T.B.; KARLEN, D.L.; TURCO, R.F.; KONOPKA, A.E. Field-scale variability of soil properties in central Iowa soils. Soil Science Society of American Journal, Madison, v.58, n.5, p. 1501-11, 1994.

CAMINHA JUNIOR, I.C.; SERAPHIM, O.J.; GABRIEL, L.R.A. Caracterização de uma área agrícola irrigada com efluente agroindustrial, através de análises químicas e da resistividade do solo. Energia na Agricultura, Botucatu, v.13, n.4, p.40-54, 2000.

CLARK, R.L.; CHEN, F.; KISSEL, D.E.; ADKINS, W. Mapping soil hardpans with the penetrometer and electrical conductivity. INTERNATIONAL CONFERENCE ON PRECISION AGRICULTURE, 5., 2000, Minneapolis. Proceedings... Minneapolis: P.C. Robert, 2000. 1 CD-ROM. 
DALGAARD, M.; HAVE, H.; NEHMDAHL, H. Soil clay mapping by measurement of electromagnetic conductivity. EUROPEAN CONFERENCE ON PRECISION AGRICULTURE, 3. 2001, Montpellier. Proceedings ... Montpellier: AgroMontpellier, 2001. 1 CD-ROM.

DOOLITTLE, J.A.; SUDDUTH, K.A.; KITCHEN, N.R.; INDORANTE, S.J. Estimating depths to claypans using eletromagnetic induction methods. Journal of Soil and Water Conservation, Ankeny, v.49, n.6, p.572-5, 1994.

FRITZ, R.M.; MAIO, D.D.; SCHUMACHER, T.E; CLAY, D.E.; CARLSON, C.G; ELLSBURY, M.M.; DALSTED, K.J. Field comparison of two soil electrical conductivity measurement systems. INTERNATIONAL CONFERENCE ON PRECISION AGRICULTURE, 4., 1998, St. Paul.

Proceedings... St. Paul: P.C. Robert, 1998. 1 CD-ROM.

GIMENEZ, L.M.; MOLIN, J.P. Desenvolvimento de um algoritmo para redução de erros em mapas de rendimento obtidos em agricultura de precisão. In: INFOAGRO 2000, Ponta Grossa. Anais... Ponta Grossa: UEPG, 2000. 1 CD ROM.

HARTSOCK, N.J.; MUELLER, T.G.; THOMAS, G.W.; BARNHISEL, R.I.; WELLS, K.L.; SHEARER, S.A. Soil electrical conductivity variability. In: INTERNATIONAL CONFERENCE ON PRECISION AGRICULTURE, 5., 2000 Minneapolis. Proceedings... Madison: American Society of Agronomy, 2000. 1 CD-ROM.

JAYNES, D.B. Improved soil mapping using electromagnetic induction surveys. In: INTERNATIONAL CONFERENCE ON PRECISION AGRICULTURE, 3., 1996, Minneapolis. Proceedings... Minneapolis: P.C. Robert, R.H. Rust and W.E. Larson, 1996. p.169-79.

KACHANOSKI, R.G.; GREGORICH, E.G.; WESENBECK, I.J. Van. Estimating spatial variations of soil water content using noncontacting electromagnetic inductive methods. Canadian Journal of Soil Science, Toronto, v.68, p.715-22, 1988.

McBRIDE, R.A.; GORDON, A.M.; SHRIVE, S.C. Estimating forest soil quality from terrain measurements of apparent electrical conductivity. Soil Science Society of American Journal, Madison, v.54, p.290-3, 1990.

MOLIN, J.P. Geração e interpretação de mapas de produtividade para agricultura de precisão. In: BORÉM, A.; GIÚDICE, M.P.; QUEIROZ, D.M.; MANTOVANI, E.C.; FERREIRA, L.R.; VALLE, F.X.R.; GOMIDE, R.L.Agricultura de precisão. Viçosa - MG: Universidade Federal de Viçosa, 2000. p.237-58.

MOLIN, J.P.; COUTO, H.T.Z.; GIMENEZ, L.M.; PAULETTI, V.; MOLIN, R.; VIEIRA, S.R. Regression and correlation analysis of grid soil data versus cell spatial data. In: EUROPEAN CONFERENCE ON PRECISION AGRICULTURE, 3., 2001, Montpelier. Proceedings... Montpelier: AgroMontpellier, 2001. 1 CD-ROM.

MOORE, M. An investigation into the accuracy of yield maps and their subsequent use use in crop management. 1998. 379 f. Thesis (Doctorate) - Silsoe College, Cranfield University, Warwick, 1998.

SUDDUTH, K.A.; KITCHEN, N.R.; DRUMMOND, S.T. Soil conductivity sensing on claypan soils: comparison of electromagnetic induction and direct methods. In: INTERNATIONAL CONFERENCE ON PRECISION AGRICULTURE, 4., 1998, Minneapolis. Proceedings... Minneapolis: Ed. P.C. Robert, 1998. p.979-90.

WILLIAMS, B.G.; HOEY, D. The use of electromagnetic induction to detect the spatial variability of the salt and clay content of soils. Australian Journal of Soil Research, Melbourne, v.25, n.1, p.21-7, 1987. 